\title{
Contra lo 'mimético' en Calímaco a partir del concepto de 'ficción de performance original'
}

Alejandro Abritta

Universidad de Buenos Aires / CONICET, Argentina alejandroabritta@gmail.com

\section{Resumen}

La división de los himnos de Calímaco entre 'miméticos' y 'no-miméticos' es estándar en la filología contemporánea, pero ha entrado en una crisis sutil en las últimas décadas. En este trabajo me propongo no solo presentar los motivos de esta crisis, sino proponer una solución desde la noción de 'ficción de performance original', presentada en Llanos (2017), que, además de resolver los problemas de fondo, vincula la colección himnódica de Calímaco con otros poemas de su época en el uso de una técnica (meta)literaria. La aplicación del concepto se ejemplifica con un análisis del Himno a Ártemis.

\section{Against the 'mimetic' in Callimachus from the concept of 'fiction of original performance'}

\begin{abstract}
The partition of Callimachus' hymns in 'mimetic' and 'not mimetic' is standard in contemporary philology but has entered a subtle crisis in the last decades. In this work I intend not only to present the reasons behind this crisis, but also to propose a solution using the concept of 'fiction of original performance', presented in Llanos (2017), which, in addition to solving the basic problem, links the Callimachus' hymnodic collection with other poems of its age in the use of a (meta-)literary technic. The application of the concept is exemplified with an analysis of the Hymn to Artemis.
\end{abstract}

Palabras clave Calímaco Himnos Ficción de performance original Ártemis

\section{Keywords}

Callimachus Hymns Fiction of original performance Artemis 
1. Respecto a esto, retomaré algunos temas que he señalado en Abritta (2014:7-9), donde no hablé de 'crisis', aunque mis observaciones presuponían una crisis teórica.

2. La cuestión está presentada en detalle y con amplia bibliografía (aunque, naturalmente, con el foco puesto sobre el himno V) en Bulloch (1985:3-13), que también es en buena medida previo al cambio en los estudios de la época heenística Una presentación más Bulloch (2010:171 73) y una útil discusión sobre el problema de la performance de la poesía de Calímaco en Morrison (2007:105-115).

3. Omito aquí el problema del cambio de metro entre los himnos líricos arcaicos y clásicos y los himnos 'miméticos', porque entiendo que la solución propuesta por Fantuzzi; Hunter (2005:27-28), es decir, que el desarrollo de las técnicas compositivas rítmico-musicales há́a difícil componer en metros complejos a los no-especialistas, basta para explicarla.

4. A priori rápidamente: en la historia de la disciplina la aparición de estos problemas tomó bastante tiempo.

5. Esta cuestión ha sido adecuadamente resumida (con referencias) en Torres (2003:261-262)

6. Una postura presentada en Falivene (1990) y Harder (1992), en ambos casos para 'rescatar' la oposición conceptual de la que se está hablando (cfr. abajo).

\section{Introducción}

La división de los himnos de Calímaco entre 'miméticos' y 'no-miméticos' es estándar en la filología contemporánea, pero ha entrado en una crisis sutil en las últimas décadas. En efecto, la noción tradicional de que algunos de los himnos 'imitan' una ocasión efectiva de performance mientras que otros son nada más que narraciones tradicionales de los dioses, si no ha sido cuestionada, sí ha sido modificada de manera profunda, aunque en general no explícita. En este trabajo me propongo no solo presentar los motivos de esta crisis, ${ }^{1}$ sino proponer una solución desde la noción de 'ficción de performance original' (Llanos, 2017) que, además de resolver los problemas de fondo, vincula la colección himnódica de Calímaco con otros poemas de su época en el uso de una técnica (meta)literaria.

\section{La crisis de la oposición 'mimético' / 'no-mimético'}

Sin detenerse en la historia de la cuestión, lo primero que debe observarse es que la distinción entre himnos miméticos y no-miméticos proviene de un contexto teórico completamente diferente del nuestro. ${ }^{2}$ No solo porque es hija de una concepción de la poesía alejandrina como una poesía erudita, casi ‘de torre de marfil', sino también porque proviene de un período en el que la influencia del contexto cultural (en general en la literatura y en particular en la que nos concierne aquí) no era un elemento fundamental en el análisis de los textos. La idea de poemas que meramente 'imitan' un rito es adecuada en una concepción de la literatura de una época como una serie de ejercicios intelectuales.

La oposición es muy sencilla y evidente hasta para un estudiante que no ha hecho más que ojear las primeras líneas de cada poema. Los Himnos 1, 3 y 4 son 'no-miméticos', porque reproducen mayormente los rasgos y la técnica compositiva de los himnos 'rapsódicos' que nosotros conservamos en la colección de Himnos Homéricos. Pueden ser considerados himnos 'narrativos', porque el grueso de su contenido está compuesto por un relato, una historia (o varias) sobre el dios que está siendo celebrado. Los otros himnos, los Himnos 2, 5 y 6, son 'miméticos', porque 'imitan' himnos líricos compuestos para ocasiones y festividades particulares. ${ }^{3}$ La imitación se manifiesta en el uso de la segunda persona para dirigirse a los celebrantes que acompañan al narrador, en la abundancia de deícticos y en la descripción del ritual y sus elementos.

A primera vista, no hay razones para poner esto en cuestión. La oposición de estilos resulta relativamente clara. No obstante, dos problemas se presentan rápidamente: ${ }^{4}$ primero, en qué medida podría hablarse de himnos 'miméticos' frente a 'no-miméticos' si los himnos de Calímaco hubieran sido efectivamente compuestos para ser ejecutados en una ocasión ritual. En ese caso, aunque seguiría habiendo una diferencia en los estilos, no sería adecuada la separación de los dos grupos. ${ }^{5}$ Más aún, insistir en que había dos grupos sería preservar una falacia teórica.

Si este primer problema es de índole 'cultural', por así decirlo, el segundo es de índole más específicamente filológica: en todos los himnos de la colección hay elementos de 'mímesis' y elementos narrativos, es decir, no puede definirse en forma contundente una oposición entre un grupo y otro, sino una diferencia solo de grado. ${ }^{6}$ Así, por ejemplo, no solo hay imitación en el Himno a Atenea, 
sino también una narración estándar en estilo rapsódico sobre la ceguera de Tiresias, mientras que, aunque el Himno a Zeus está compuesto casi por completo por un relato, las preguntas y respuesta en los vv. 6-8 pueden considerarse un elemento propio de una performance efectiva. ${ }^{7}$

No hay solución posible al primer inconveniente desde la perspectiva teórica que sostiene la oposición 'mimético' vs. 'no-mimético'. Bulloch (2010:173) presenta el argumento más extendido de sus defensores contra quienes han sostenido la ejecución de los poemas:

\section{Callimachus' mimetic hymns are so specific about such momentary details as the neighing of the horses that are pulling the festival chariot in the Hymn to Athena [vv. 2-3], that they cannot possibly have been written for an actual ceremony...}

El problema con esto es que no puede defenderse sin evidencia externa sobre cómo eran los himnos en las festividades en las que eran supuestamente cantados. Cualquiera que haya visto una ceremonia de apertura de alguno de, por ejemplo, los Juegos Olímpicos contemporáneos sabe que la coordinación entre diferentes participantes en un rito puede alcanzar niveles insospechados. No resultaría nada difícil coordinar el comienzo del Himno a Atenea con el movimiento del carro que llevaba su estatua.

Esto, no obstante, no debe llevar a pensar que se está defendiendo la posición de quienes proponen una ejecución efectiva de los himnos sobre la base de los marcadores de performance en ellos, pero no porque un rasgo performativo podría ser también una imitación literaria (como sugiere Hunter, 1993:3132). Sostener semejante cosa no es más que reproducir el marco teórico de la oposición 'mimético' / 'no-mimético' con otras palabras: suspender el juicio respecto a si los marcadores de performance son 'reales' o simples 'imitaciones' no es abandonar el marco teórico, es solo decir que no contamos con evidencia suficiente para resolver una cuestión dentro de él.

Ahora, dado que el problema vale para absolutamente todos los himnos de Calímaco (y quizás para todos los poemas de la época helenística), puesto que en todos hay al menos un marcador de performance, lo que esto implica es que en este marco teórico de hecho no se puede alcanzar conclusiones sobre ninguno de ellos. Es evidente que esta es la crisis de la que se habló al comienzo de este trabajo: un marco teórico que no puede dar respuestas sobre un aspecto que considera fundamental de su objeto de estudio es un marco teórico que ha fracasado.

Una respuesta ante esta dificultad de las categorías estancas es trasladar la noción de 'mimético' no ya a los poemas en su conjunto sino a determinados recursos. Así se resuelve el problema que la ejecución o no-ejecución de un himno presenta (porque puede haber recursos 'miméticos' también en un himno efectivamente ejecutado), pero a costa de sacrificar una posición sobre la cuestión de fondo, es decir, cuál es la relación de la poesía de la época helenística con el contexto de performance. Tanto Falivene (1990:107-108 y passim) como Harder (1992:384n.2) pasan de largo este inconveniente simplemente convirtiendo en postulado lo que la división tradicional se proponía extraer de los propios textos, esto es, que los himnos no fueron compuestos para su performance en un festival.

Esto es porque 'mimético' no es meramente una forma de decir 'imitativo': es una forma de convertir 'imitativo' en una técnica compositiva. Un himno
7. Falivene (1990:108-113) realiza un análisis en este sentido comparando los Himnos 2 y 4. 
8. La distinción ha sido elaborada en Oesterreicher (1997). Es importante notar que no es una mera oposición oralidad / escritura, sino una de modos de habla que suelen darse en un soporte o en otro, pero no están necesariamente vinculados a ellos. Un texto escrito puede tener (y suele suceder que tiene) lenguaje de inmediatez y un texto oral, lenguaje de distancia.

9. Acosta-Hughes (2010) ha realizado estas mismas observaciones.

10. Un actor que finge ser un médico no está imitando a un médico y un chico que finge ser un soldado no está imitando a un soldado. Ambos están adoptando un rol específico en un escenario ficticio que, por supuesto, implica realizar una serie de acciones observadas en el escenario real, pero no se limita a una mera imitación de ellas. 'mimético' 'imita' una ejecución real no porque tiene rasgos de una ejecución real, sino porque incorpora una serie de elementos que en una ejecución real estarían implícitos o se extraerían del contexto. El concepto entra en crisis cuando se lo aplica a recursos puntuales o cuando se presenta la posibilidad de una ejecución real por el sencillo motivo de que entonces no se puede hablar de una 'imitación' que fundamente lo 'mimético'; un deíctico en Calímaco puede ser nada más que una ficción que 'imita' un deíctico en, por ejemplo, un poema pindárico solo en la medida en que no sea posible decir que un deíctico en Píndaro es un recurso 'mimético' y que la poesía de Calímaco nunca fue ejecutada.

Todo este problema tiene un origen muy simple: en lugar de atender a las técnicas compositivas efectivamente utilizadas por los poetas de la época helenística, los filólogos han encarado el análisis de su literatura a partir del supuesto falso de que el florecimiento de una cultura erudita modificó de manera radical la manera de escribir poesía en el mundo griego. Sin embargo, no hay evidencia de esto. La re-circulación de la poesía por escrito, la combinación de lenguaje de inmediatez (propio de lo oral) con lenguaje de distancia (propio de lo escrito $)^{8}$ y la composición con un ojo puesto en la re-performance son rasgos de la poesía griega al menos desde la época arcaica. ${ }^{9}$ Esto no puede sorprender a nadie y si quienes investigan hoy la época helenística no lo toman suficientemente en cuenta no es más que por el hecho de que dice menos de la época helenística que de las épocas precedentes.

Pero la inversa también es verdadera. Un aspecto esencial de la poesía griega arcaica, como la definición del género de un poema a partir de su contexto de performance, continúa funcionando en el período helenístico. Esta continuidad choca, sin embargo, con el cambio en el contexto cultural que hace que determinados contextos de performance tradicionales desaparezcan: ante este problema, los poetas respondieron generando el contexto de performance pretendido de sus poemas con las propias palabras de los textos. Es lo que se ha denominado 'ficción de performance original' (FPO).

\section{El concepto de FPO y los Himnos de Calímaco}

A primera vista, el concepto de FPO no parece distinguirse demasiado del de 'mímesis'. Se dirá: si se está 'fingiendo' un contexto de performance, ¿por qué no decir simplemente que se está 'imitando'? La respuesta es sencilla: 'fingir' no es 'imitar', es crear un ámbito específico para una acción determinada. ${ }^{10}$ Esta ficción es independiente del ámbito en que la acción se realiza: se puede fingir que un himno leído en la corte de Ptolomeo está siendo ejecutado en un festival en Cirene y se puede fingir, al leer en una biblioteca un poema escrito, que se lo está escuchando en el lugar donde fue presentado originalmente.

El concepto de FPO, sin embargo, va más allá y es más complejo que eso, porque un himno compuesto para un festival en Cirene también puede elaborarse (o, eventualmente, re-elaborarse) incorporando los marcadores necesarios para que en su transmisión secundaria (por escrito o en re-performances posteriores) el contexto original sea reconocible. Esta es una de las ventajas claves sobre la oposición 'mimético' / 'no-mimético': un himno no puede 'imitar' su contexto efectivo de performance, pero sí puede ser compuesto de manera tal que su contexto efectivo de performance sea reconocible en la transmisión secundaria. De hecho, FPO implica que es intrascendente si hubo o no ejecución 
original: el receptor (helenístico culto) de, por ejemplo, el Himno 2 de Calímaco lo leerá o escuchará siempre asumiendo que es un texto compuesto para el festival de las Carneias. ${ }^{11}$ Esto no significa que el problema de la performance de los himnos no sea importante: significa que no es un problema específico del ámbito de la filología, sino una más general de las ciencias de la cultura, ${ }^{12}$ que no puede resolverse con evidencia interna de los propios poemas.

Es necesario explicar esto con algún detalle, porque constituye la respuesta que el concepto de FPO ofrece frente a la crisis de la oposición tradicional. Como se ha notado, los filólogos han discutido largamente sobre la ejecución efectiva de los himnos de Calímaco. Pero lo han hecho casi siempre por el texto y desde el texto. Así, por ejemplo, se ha considerado que el referente de

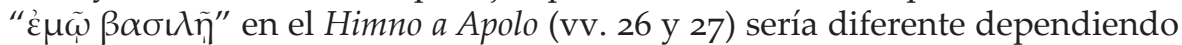
de si el himno es 'mimético' (es decir, si está destinado a una audiencia erudita de Alejandría, en cuyo caso se debería pensar en algún Ptolomeo) o fue efectivamente ejecutado (en cuyo caso se debería pensar en Magas, el rey de Cirene) (sobre esta cuestión, $c f r$. Morrison, 2007:108-109 con sus referencias). El problema se ha intentado resolver a partir del análisis del propio poema y sus alusiones. Esto, por supuesto, en el contexto de la teoría estándar. Pero en el contexto de una teoría basada en la noción de FPO, la hipótesis de Selden (1998:384-385) de un referente variable no solo se hace posible, sino inevitable. Lo que es más importante, esto no sucede en el sentido que propone el autor de que en la (re)circulación del texto en Alejandría la ambigüedad de la expresión permitiría que se entendiera como referida a uno de los Ptolomeos: en el nivel literal, esto es altamente improbable. Un himno (que se construye a sí mismo como) cantado en Cirene sobre los reyes batíadas, con los antecedentes imposibles de ignorar de las Píticas 4 y 5 de Píndaro, no puede tener otro referente que un rey de Cirene. En el contexto de performance original. Pero aquí entra en juego en toda su complejidad la técnica poética de Calímaco. En un nivel meta-literario, en el que un receptor secundario (que, si el himno no fue ejecutado, sería obviamente el receptor primario) entiende los marcadores de performance como una estrategia de construcción de un contexto de performance, la referencia ambigua quiebra, por así decirlo, la ficción. " $\dot{\varepsilon} \mu \tilde{\omega}$ $\beta \alpha \sigma \iota \lambda \tilde{\eta}^{\prime \prime}$ puede tener múltiples referentes simultáneos en distintos niveles. En este sentido, el referente de la expresión es variable, pero no horizontalmente como propone Selden (es decir, conforme el poema se mueve en diferentes ámbitos de recepción), sino verticalmente (es decir, conforme el receptor cambia su perspectiva de análisis sobre el poema). Aunque esta posibilidad existe en una teoría tradicional basada en la noción de 'mímesis', solo funciona si se incorporan varias observaciones ad hoc.

La cuestión de la ejecución efectiva se reduce así a un problema anecdótico. ${ }^{13}$ La construcción de un contexto de performance original garantiza que los marcadores utilizados por el poeta deben ser entendidos no como 'imitativos' sino como elementos constituyentes del himno. De esta manera, el segundo inconveniente mencionado, el de la conversión del concepto de 'mimético' como categoría no de textos sino de recursos, desaparece. El contexto original de performance en una perspectiva basada en la noción de FPO se construye a partir de una serie (indefinida) de marcadores específicos, que van de referencias al contexto de ejecución (como pronombres, deícticos, vocativos y descripciones) hasta el mismísimo metro del texto. ${ }^{14}$ Pero no hay poemas con y sin un contexto de performance, porque esto implicaría que hay poemas con y sin género, lo que es absurdo. Desde el himno 'rapsódico' a Delos hasta el himno 'híper-mimético' a Apolo, todos los poemas conservados construyen su contexto de performance utilizando recursos propios.
11. Sobre este festival, cfr. Torres (2003) con bibliografía. Por razones de espacio, omito una presentación detenida sobre el asunto.

12. Entendiendo, por supuesto, que la filología es una de las ciencias de la cultura que puede aportar datos para la solución de este problema. La única salvedad es que esos datos no pueden provenir de los propios himnos. 13. Una vez más, esto no signifi-
ca que sea una cuestión menor,
significa sólo que lo es a los fines
específicos del análisis del poema.
14. Pienso en particular, para el caso de Calímaco, en el uso de dísticos elegíacos en el Himno a Atenea: existen rastros (aunque pocos) de una tradición himnódica en este metro en la argólide, es decir, la ubicación del ritual en la que el himno se inscribe (cfr. Bulloch, 1985:36-37). 
Las ventajas del nuevo enfoque no terminan ahí. La construcción de un contexto de performance no es un proceso lineal y sencillo. Los poetas incorporan marcadores de performance complejos, a veces ambiguos, que enriquecen sus composiciones, sin por ello diluir la reconocibilidad del contexto pretendido. Así, por ejemplo, como he observado en Abritta (2014), en el Himno a Zeus Calímaco manipula una serie de elementos tradicionales de los Himnos Homéricos, incorporando además elementos de la poesía lírica encomiástica para adecuar el poema al nuevo contexto cultural. Allí puse el foco en el valor ritual de esta técnica, pero ese valor ritual puede ser visto como una forma de FPO, en la medida en que construir un contexto de performance para un himno también es construir un espacio ritual en donde este es ejecutado. Lo notable en el caso del Himno a Zeus es que esa construcción no es solo una reconstrucción de un ámbito tradicional, sino la producción de un espacio nuevo de performance, en el que se combina la religión tradicional con el nuevo contexto ptolemaico. Para terminar este trabajo, puede resultar útil estudiar con algo más de detalle la forma en que Calímaco lleva esta técnica al extremo en el Himno a Ártemis.

\section{El contexto imposible del Himno a Ártemis}

El Himno a Ártemis ha atraído a la crítica por su grado de 'dispersión mitológica' en lo que hace al culto de la diosa. En efecto, mientras que la mayoría de los himnos hexamétricos (y en general) suelen relatar una única historia del dios al que invocan, ${ }^{15}$ el Himno a Ártemis recorre la biografía de la diosa desde su nacimiento hasta el momento en que su poder se ha extendido sobre todo el mundo griego. Esto, a su vez, implica que en el poema se combinan una serie de alusiones a diferentes lugares de culto en el mundo helénico (cfr. Rodoni, 2015 con sus referencias) haciendo imposible identificar una ocasión o ritual específico para el que pudiera haber sido compuesto. En una perspectiva tradicional, estos dos elementos se explican sencilla e inelegantemente: por un lado, el carácter no-mimético del himno justifica la falta de alusión a un contexto de performance; por el otro, la dispersión mitológica se entiende como el resultado de la típica búsqueda helenística de originalidad e innovación (McKay, 1963).

Que esta manera de ver las cosas está atravesada por preconcepciones académicas injustificadas ha quedado demostrado con el análisis del himno realizado por Bing y Uhrmeister (1994). Los autores estudian el texto partiendo del supuesto de que la unidad del poema no puede buscarse en el relato, sino que debe apreciarse en lo que el himno hace como un todo. Gracias a su detallado estudio es posible afirmar que el Himno a Ártemis respeta el principio estándar de que los himnos hexamétricos cuentan una única historia del dios al que celebran, solo que, en este caso, esa historia es la de cómo la diosa llegó a ser una figura venerada en todo el mundo griego.

Este enfoque más adecuado ha llevado a Alejandra Rodoni (2015) a cuestionarse sobre la pluralidad de alusiones a diferentes tradiciones y cultos en el himno que, como se ha mencionado ya, se utilizaba tradicionalmente como argumento a favor del carácter 'no-mimético' de un poema que no podría estar imitando un rito de ninguna región o festividad específica. Siguiendo la propuesta de Petrovic (2010), que rechaza la idea de panhelenismo 'experimental' por mor del juego intelectual, la autora propone que la combinación de cultos y aspectos de la diosa en el himno de Calímaco debe entenderse como una 
adecuación a las concepciones religiosas y culturales en el mundo ptolemaico. La multitud de lugares de culto de Ártemis, en un ámbito panhelénico como el de la Alejandría helenística, demanda un himno que ponga énfasis en esa amplitud. ${ }^{16}$

Aunque estos cambios de enfoque proveen una perspectiva del Himno a Ártemis más adecuada que la 'dispersión' tradicional, es interesante notar que dejan fuera el problema de la performance del himno. ${ }^{17}$ En el marco de la oposición 'mimético' / 'no-mimético' esto es de esperarse: no hay rasgos performativos en el poema que permitan defender una ocasión o contexto específico. De hecho, la introducción de una pluralidad de lugares de culto sigue siendo un argumento válido contra una ejecución efectiva: aunque un himno panhelénico sería probablemente adecuado para la Alejandría ptolemaica, no tenemos registro de una tradición de este tipo de composiciones para defender este tipo de adecuación. ${ }^{18}$

La discusión es, por supuesto, ociosa. No habiendo evidencia de ninguna clase sobre dónde o si se ejecutó el Himno a Ártemis, cualquier argumento que se presente depende de premisas que determinan la interpretación de algún pasaje del texto. Así, por ejemplo, los vv. 237-258, el final de la parte central, se concentran en Éfeso, lo que podría sugerir una performance situada allí y acaso encomendada por Ptolomeo en honor a Arsínoe II, dada la conexión de la reina con la zona (Stephens, 2015:19-20). La especulación podría apoyarse en conexiones entre el Himno a Ártemis y el Himno a Delos (por ejemplo, la similitud entre los vv. 37 y 168 de uno y otro propuesta por Stephens, 2015:127), en la recuperación del motivo de la danza circular de los vv. 170-182 en el v. 240, etc. Pero estas sutilezas no pueden nunca definir la cuestión: solo si se interpretan a partir de la premisa (nunca explicitada) de que ciertos elementos de un himno implican una performance efectiva pueden estar indicando una performance efectiva. En otras palabras, argumentar a favor de una performance efectiva es siempre e inevitablemente una petitio principii.

En el marco propuesto en este trabajo basado en la noción de FPO, el inconveniente se resuelve y permite integrar las interpretaciones mencionadas de manera simple y elegante. Dejando de lado el irresoluble problema del contexto hipotético de una hipotética ejecución efectiva, la pregunta que debemos realizar es cuál es el contexto que el himno construye para sí. La respuesta es 'ninguno y todos'. La forma en que Calímaco configura la figura de Ártemis como una diosa cuyo poder abarca todo el mundo helenizado y multiplica las alusiones a ritos y cultos diferentes indica que el contexto de performance que se está construyendo no es un contexto tradicional himnódico, local, asociado a un ritual específico. No es que el Himno a Ártemis se elabore tomando en cuenta el carácter panhelénico del mundo cultural alejandrino y la amplitud del culto a la diosa, sino que construye un contexto de performance adecuado a ese mundo y a esa amplitud. En una tradición con tintes extremadamente localistas como la de la himnodia griega, un poema que una y otra vez se desplaza, haciendo imposible identificar un ritual o una festividad específica, está de hecho construyendo un ritual nuevo propio de un espacio multicultural.

El cambio de perspectiva no solo aúna los avances realizados por Bing y Uhrmeister (1994), Petrovic (2010) y Rodoni (2015) en un solo modelo, sino que además lo hace en un modelo que no introduce una diferencia radical con la tradición de la himnodia griega. En efecto, todos los himnos de la tradición atienden a su contexto de performance y, en particular, los himnos ocasionales atienden al rito y la locación para los que fueron concebidos. Si Calímaco
16. No sin antecedentes en la tradición como demuestra, por ejemplo, la enumeración de lugares de culto en el Himno Homérico a Apolo (vv. 30-44).

17. De hecho, la palabra 'performance' no aparece en ninguno de mance no aparece en ninguno
los tres artículos mencionados.

18. Nótese, en efecto, que, aunque el resto de los himnos de Calímaco combinan tradiciones de diferentes lugares (piénsese en el comienzo del Himno a Zeus), ninguno lo hace en la medida y la forma en que lo hace el Himno a Ártemis, donde la combinación es fundamental para la elaboración del poema. 
demuestra que es consciente de esto en el Himno a Apolo, en el Himno a Ártemis manipula estas posibilidades al máximo: en lugar de elaborar un poema para un contexto indefinido (al estilo de los Himnos Homéricos) o elaborar un poema para una ocasión específica, construye un nuevo tipo de contexto ritual para un nuevo tipo de religión en un nuevo contexto cultural. La performance así elaborada es, de este modo, tradicional, puesto que incorpora elementos del mito y el culto a Ártemis de todo el mundo griego, y completamente innovadora, puesto que los combina en un todo coherente en una celebración única.

\section{Conclusiones}

Cuando una teoría entra en crisis suceden con frecuencia dos cosas: la teoría persiste durante mucho tiempo como un esqueleto sin significado y la solución a la crisis es intuida bastante antes de ser formulada. En la bibliografía específica, la idea de que los himnos de Calímaco construyen su propio contexto de performance puede rastrearse en trabajos de las últimas dos o tres décadas. Estudios que ponen énfasis en la preocupación del poeta por reproducir tradiciones rituales, por enriquecer sus textos con elementos de otros géneros performativos y de adecuar sus himnos al nuevo contexto cultural son estudios que pueden ser incorporados a una perspectiva basada en la noción de FPO con éxito, permitiendo la construcción de una teoría nueva y poderosa para el análisis de la poesía de Calímaco. Y, además, dejar de lado problemas trillados que deberíamos haber superado hace tiempo. 


\section{Bibliografía}

"Abritta, A. (2014). "Hacia una historia coral de la himnodia griega: experimentos literarios y memoria cultu(r)al en los Himnos de Calímaco", Anales de Filología Clásica 27, 5-18.

" Abritta, A. (2017). "Conjeturas sobre una historia coral de la himnodia hexamétrica griega". En: Torres, D. A. (ed.) La himnodia griega antigua. Culto, performance y desarrollo de las convenciones del género. Buenos Aires: Facultad de Filosofía y Letras, UBA, 81-108.

" Acosta-Hughes, B. (2010). "The Prefigured Muse: Rethinking a Few Assumptions on Hellenistic Poetics". En: Clauss, J. J.; Cuypers, M. (eds.). A Companion to Hellenistic Literature, Malden: Wiley-Blackwell, 81-91.

» Bing, P.; Uhrmeister, V. (1994). "The Unity of Callimachus' Hymn to Artemis", JHS114, 19-34.

" Bulloch, A. W. (1985). Callimachus. The Fifth Hymn. Cambridge: Cambridge University Press.

" Bulloch, A. W. (2010). "Hymns and Encomia". En: Clauss, J. J.; Cuypers, M. (eds.). A Companion to Hellenistic Literature. Malden: Wiley-Blackwell, 166-180.

"Falivene, M. R. (1990). "La mimesi in Callimaco: Inni II, IV, V e VI", QUCC 36, 103-128

» Fantuzzi, M.; Hunter, R. (2005). Tradition and Innovation in Hellenistic Poetry. Cambridge: Cambridge University Press.

» Harder, A. M. (1992). "Insubstantial Voices: Some Observations on the Hymns of Callimachus", CQ 42, 384-394.

» Hunter, R. (1993). "The Presentation of Herodas' Mimiamboi", Antichthon 27, 31-44.

"Llanos, P. M. (2017). "Ficción de performance original en el exordio de Argonáuticas de Apolonio de Rodas", Synthesis 24, e013.

" McKay, K. J. (1963). "Mischief in Kallimachos' Hymn to Artemis", Mnemosyne 16, 243256.

"Morrison, A. D. (2007). The Narrator in Archaic Greek and Hellenistic Poetry. Cambridge: Cambridge University Press.

" Oesterreicher, W. (1997). "Types of orality in Text". En: Bakker, E.; Kahane, A. (eds.) Written Voices, Spoken Signs. Tradition, Performance and the Epic Text, Cambridge. Ma.: Harvard University Press, 190-214.

» Petrovic, I. (2010). "Transforming Artemis: from the Goddess of the Outdoors to City Goddess". En: Bremer, J.; Erskine, A. (eds.) The Gods of ancient Greece. Identities and transformations. Edinburgh: Edinburgh University Press.

" Rodoni, M. A. (2015). "Ártemis y la ciudad en el Himno a Ártemis de Calímaco", CFC(G) 25, 215-222.

»Selden, D. L. (1998). "Alibis", CA 17, 289-412.

"Stephens, S. A. (2015). Callimachus. The Hymns. Oxford: Oxford University Press.

" Torres, D. (2003). "El Himno a Apolo de Calímaco: Composición ocasional y aspectos del culto", Lexis 21, 261-277. 
